\title{
Subungual Elastofibroma
}

\author{
Eckart Haneke ${ }^{a, b, c}$ \\ ${ }^{a}$ Department of Dermatology, Inselspital, University of Berne, Bern, Switzerland; ' Dermatology Practice \\ Dermaticum, Freiburg, Switzerland; 'Centro de Dermatología Epidermis, Instituto CUF, Porto, Portugal
}

\section{Established Facts}

- Subungual connective tissue nevi are very rare.

- Only two remotely similar cases of subungual elastoma/elastofibroma have been described

\section{Novel Insights}

- This is the third case of a subungual elastofibroma, which stands out by its enormous number of elastic fibers that stood out by their thin diameter.

\section{Keywords}

Subungual elastofibroma · Nail tumors · Connective tissue nevi - Onychopathology $\cdot$ Onychodermis

\section{Abstract}

Cutaneous elastofibroma is part of the connective tissue nevus complex. Two subungual cases remotely similar to the one presented here have been described before. This patient presented with an unusual form of subungual elastofibroma of the big toe, which was surgically removed. Histopathology revealed a connective tissue tumor extremely rich in very fine elastic fibers. Their relationship to oxytalan and elaunin fibers is discussed as is the potential association of this nail bed lesion with the onychodermis.

(c) 2020 S. Karger AG, Base

\section{Introduction}

The subject of cutaneous elastoma/elastofibroma is still somewhat vague. Most cases reported were elastofibroma dorsi, which is a clearly defined reactive entity with a very characteristic histopathology and electron microscopy. In contrast, connective tissue nevus/collageno$\mathrm{ma}$ /elastofibroma occurs isolated in the skin as single or, more often, as multiple lesions. In the rare autosomal dominant Buschke-Ollendorff syndrome, multiple connective tissue nevi with a variable degree of elastic fiber increase are associated with osteopoikilosis. Subungual elastofibroma has only been described twice $[1,2]$. We observed a subungual elastofibroma that stood out from the published cases by its enormous proportion of elastic fibers and their very fine structure.

\section{Case Report}

A 54-year-old woman presented at our specialized nail consultation for a tender left big toenail. This interfered with daily activities, workouts, and mountain hiking. She was otherwise healthy, and there was no remarkable medical history.

Clinical examination revealed a yellowish, thickened, and slightly overcurved left big toenail with marked onycholysis (Fig. 1). It was tender on pressure but symptomless at rest and at night. As the clinical findings did not allow for a diagnosis to be

karger@karger.com
www.karger.com/sad
Karger




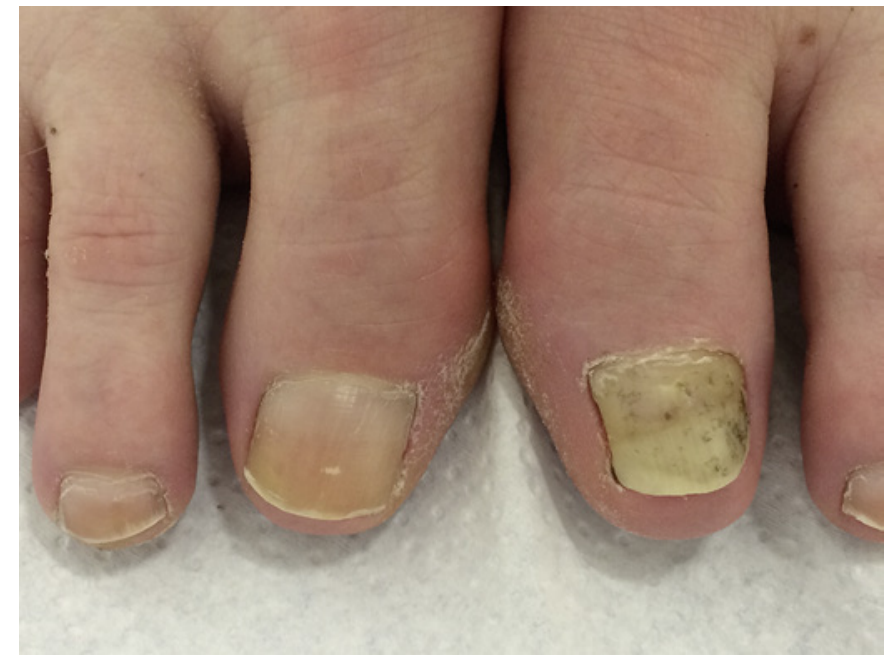

Fig. 1. Subungual elastofibroma. The left big toenail is yellow, thickened, intransparent, overcurved, and onycholytic. Both big toes show a moderate hallux valgus interphalangeus.

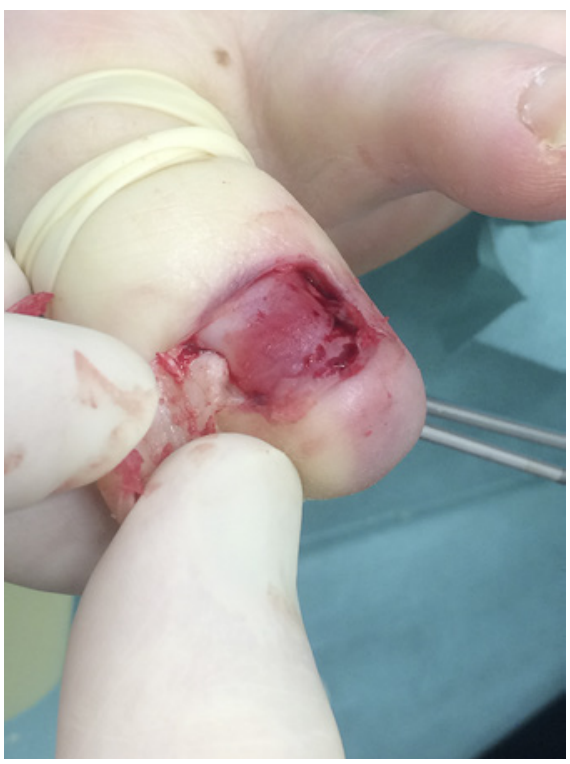

Fig. 3. Subungual elastofibroma. After reflection of the nail, a slight bulging of the nail bed is visible.

made, the onycholytic nail was cut, demonstrating a markedly shrunken nail bed and a distal bulge (Fig. 2). Probing exhibited a firm elevation in the nail bed dermis, suggestive of a subungual tumor. Two months later, the nail had regrown approximately 2 $\mathrm{mm}$, still exhibiting a markedly shortened nail bed and distal bulge.

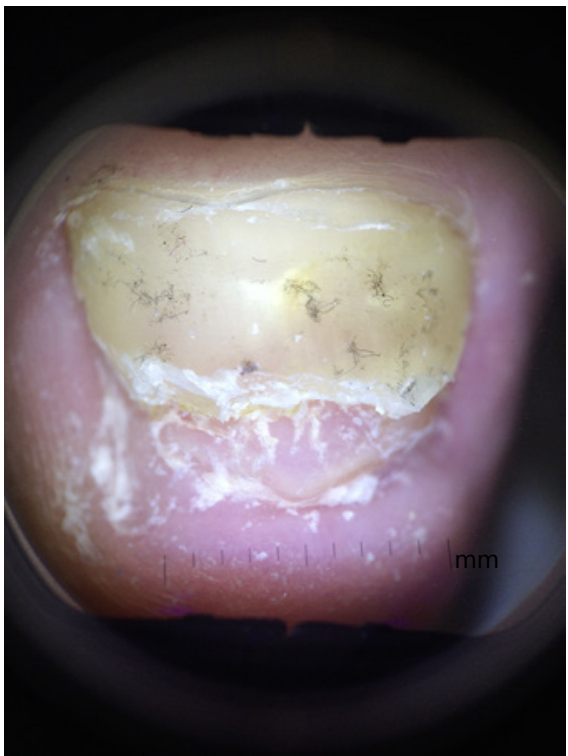

Fig. 2. Subungual elastofibroma. Directly after cutting the onycholytic nail away, a disappeared nail bed and a pronounced distal bulge impeding normal nail growth are seen.

Under proximal block anesthesia using $3 \mathrm{~mL}$ ropivacaine $1 \%$, the nail was subtotally avulsed by the proximal approach, revealing a subungual firm node occupying more than $80 \%$ of the centralmedian portion of the nail bed dermis (Fig. 3). A semicircular incision was made at its distal border to raise a short U-shaped nail bed flap for extirpation of the lesion. The tumor appeared as an ivorycolored firm elastic lesion that was mostly continuous with the overlying epithelium and dissection from it was difficult, resulting in small defects of the overlying nail bed. However, its limitation to the underlying bone was smooth and dissection easy. The defect could be partially sutured with $6-0$ absorbable stitches. The nail plate was replaced and fixed with 4-0 polypropylene stitches, which were removed after 4 weeks. Healing of the nail bed was uneventful, and the nail regrew to about 3 quarters of its normal length without onycholysis. After 2 years, this had stabilized with no further outgrowth of the nail. There was no recurrence after 4 years postoperatively.

The surgical specimen was fixed in buffered $4 \%$ formalin and paraffin-embedded. Four microsections were stained with $\mathrm{H} \& \mathrm{E}$, PAS, and Weigert's elastic stain, revealing a dense and cellular connective tissue. The fibroblasts had somewhat larger, angulated to slightly stellate nuclei, but neither atypia nor mitoses were present (Fig. 4). Elastic stain revealed a very high amount of fine wavy fibers (Fig. 5). The whole lesion was strongly and diffusely positive for CD10 except for vessel walls, muscles, and nerve bundles (Fig. 6). CD34 staining was mainly positive around blood vessels; the tumor itself was negative to weakly positive. These findings permitted the diagnosis of a subungual elastofibroma. 


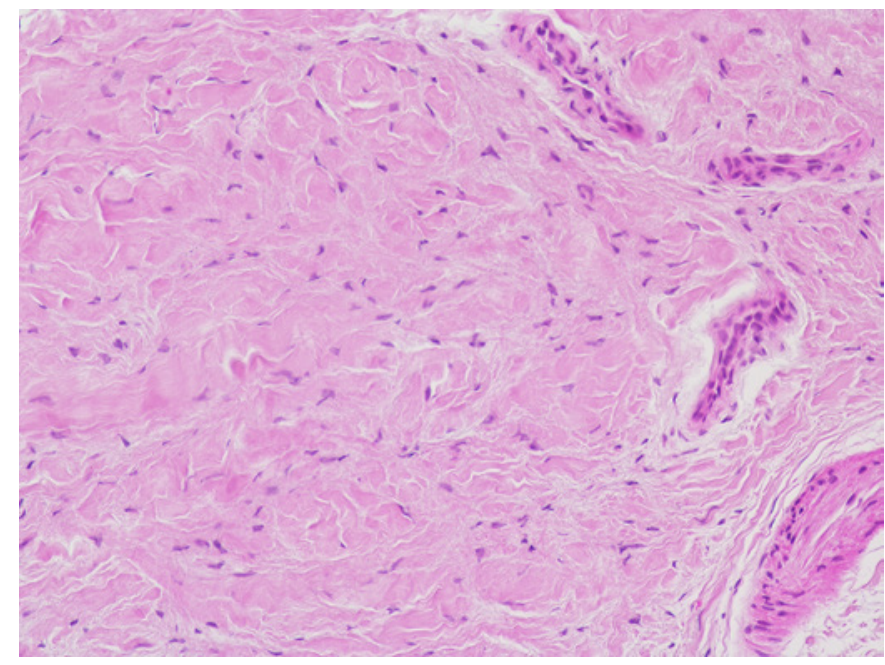

Fig. 4. Subungual elastofibroma. Histopathology of the H\&E sections. High magnification reveals dense eosinophilic collagen with many fibroblasts that display angulated to stellate nuclei without atypia. $H \& E, \times 200$.

\section{Discussion}

Dermatofibrosis lenticularis disseminata - which is now understood as connective tissue nevus or elastofibroma - in association with osteopoikilosis was described by Buschke and Ollendorff in 1928 [3]. Nonsyndromic elastoma was reported in a child in 1930 [4]. It is also called elastic nevus or connective tissue nevus $[5,6]$. Because of its variable amount of collagen fibers, the term elastofibroma may be more appropriate. Except for elastofibroma dorsi, which is thought to be reactive to chronic repeated trauma, most cases are multiple, and some are observed in association with peculiar round bone densities called osteopoikilosis, representing the autosomal dominant Buschke-Ollendorff syndrome [7]. Histopathology shows dense collagen tissue with an increased amount of elastic fibers that may be of normal thickness or coarser than normal and show fragmentation [8]. No nail involvement was observed in any of these patients.

To the best of our knowledge, only 2 cases of subungual elastofibroma have hitherto been described $[1,2]$. The first case from Greece concerned a 60-year-old male dentist with an asymptomatic color change in his left index fingernail bed. Histopathology of a $4-\mathrm{mm}$ punch biopsy revealed abundant wavy, fragmented, and agglutinated elastic fibers in the mid-dermis. Alcian blue was positive. These findings were interpreted as a connective
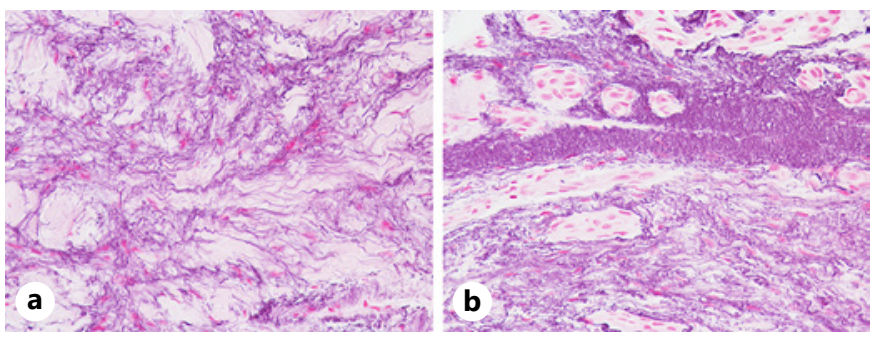

Fig. 5. Subungual elastofibroma. Weigert's elastic stain reveals abundant fine elastic fibers. a Marked increase in fine and wavy elastic fibers. b Concentration of fine elastic fibers. Weigert's elastic stain. $\times 400(\mathbf{a}), \times 200(\mathbf{b})$.

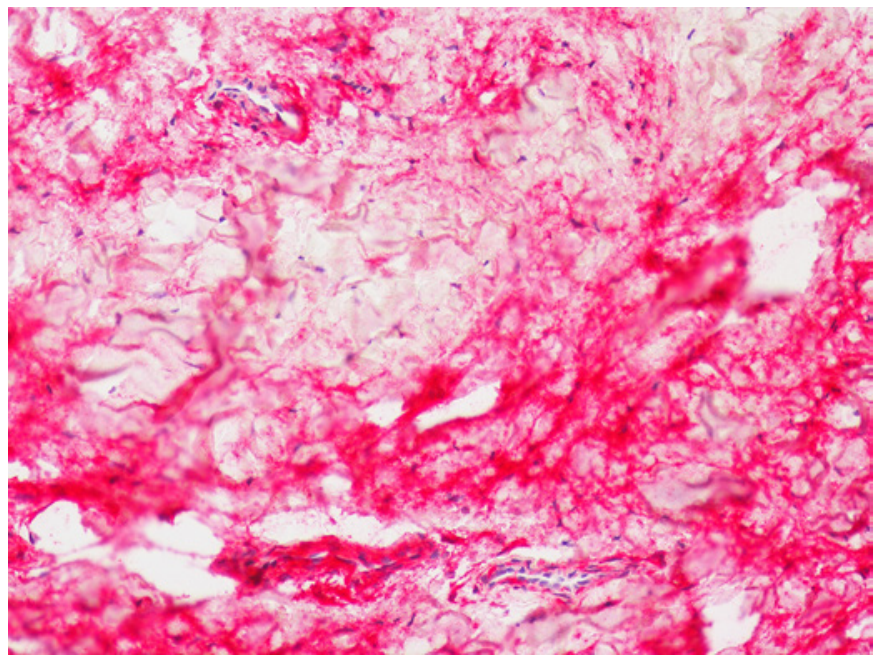

Fig. 6. Subungual elastofibroma. Immunohistochemical demonstration of CD10. CD10 is strongly and diffusely demonstrated in the tumor. CD10, $\times 100$.

tissue nevus of mixed type, that is, elastin and proteoglycan.

The second case from the USA was of a 64-year-old immunocompromised man with a subtle ivory discoloration under his right koilonychotic thumbnail. Reflection of the nail revealed a well-circumscribed white papule. Histopathology exhibited a small area of increased wavy to curved elastic fibers in the nail bed. The fibers were mostly of normal thickness.

In contrast to the 2 patients mentioned above and to elastofibromas in the Buschke-Ollendorf syndrome [7], the amount of elastic fibers was much higher in the present case. Individual fibers were considerably thinner, resembling oxytalan fibers $[9,10]$. Many of them were ar- 
ranged in dense masses, in which nerves and vessels stood out as "holes" (Fig. 5c, d). Demonstration of CD10, a marker for onychodermis [11, 12], was strongly and diffusely positive, whereas CD34 was almost exclusively restricted to perivascular connective tissue (Fig. 6a, b). The CD10-positive cells were called onychofibroblasts [11] as they appear to be specific for the nail bed and matrix. Interestingly, an immunohistochemical study on elastin and $\mathrm{C} 10$ in the nail bed and matrix showed a higher amount in the nail bed dermis than in the matrix [13]; however, the immunohistochemical demonstration of elastin does not yield the same pattern as an elastic stain. Whether this case is a connective tissue nevus of onychofibroblasts ("elastoonychofibroma") remains, however, a speculation. Further, the fibers in this case resembled both oxytalan and elaunin fibers; the former are composed exclusively of microfibrils and devoid of amorphous elastin ground substance, whereas the latter have less elastin than mature elastic fibers.

The differential diagnosis of elastofibroma is varied but limited in the present case due to its exceptional localization. Solar elastoma is a nodular form of solar elastotic degeneration and does not occur under the nail [14]. Dermatofibroma (histiocytoma) may sometimes have an increased amount of elastic fibers, but histiocytoma is surprisingly rare under the nail [15]. Superficial acral fibromyxoma is an insidiously growing lesion without an increase of elastic fibers. Xanthoma is also a yellowish flat lesion with foamy xanthoma cells. Smooth muscle hamartoma is a tender, often cold-sensitive, and contractile lesion, but it was not described in subungual localization. Angioleiomyoma may occur under the nail and is tender upon vigorous palpation; histologically, it is a round compact tumor made up of smooth muscle cells. Glomus tumors are characterized by their marked pain and their specific pathology. Subungual myxoid pseudocysts do not extend into the nail bed. A variety of other nodular lesions can be safely excluded by histopathological examination [15].

In summary, a subungual elastofibroma of the type described here has apparently not been reported before. Histopathology with elastic stain is required to make the diagnosis.

\section{Statement of Ethics}

This research complies with the guidelines for human studies and animal welfare regulations and was conducted ethically in accordance with the World Medical Association Declaration of Helsinki. The patient has given her written informed consent to publish photos and details of the case.

\section{Conflict of Interest Statement}

The authors have no conflicts of interest to disclose.

\section{Funding Sources}

The authors did not receive any funding.

\section{References}

1 Aroni K, Aivaliotis M, Davaris P. Isolated connective tissue nevus originating subungually: report of a unique case. J Dermatol. 2001;28(12):765-6.

2 Wolner ZJ, Liebman TN, Lowenstein EJ. Acquired elastoma in subungual location. Dermatol Online J. 2017;23(9):11.

3 Buschke A, Ollendorff H. Ein Fall von Dermatofibrosis lenticularis disseminata und Osteopathia condensans disseminata. Dermatol Wschr. 1928;86:257-62.

4 Weidman FD, Anderson NP, Ayres S. Juvenile elastoma. Arch Dermatol. 1933;28(2): 182-9.

5 Saussine A, Marrou K, Delanoé P, Bodak N, Hamel D, Picard A, et al. Connective tissue nevi: an entity revisited. J Am Acad Dermatol. 2012;67(2):233-9.

6 McCuaig CC, Vera C, Kokta V, Marcoux D, Hatami A, Thuraisingam T, et al. Connective tissue nevi in children: institutional experience and review. J Am Acad Dermatol. 2012; 67(5):890-7.
7 Pereira M, Leite A, Osório Ferreira E, Duarte AF, Haneke E, Correia O. Visual diagnosis: connective tissue nevus and osteopoikilosis. Pediatr Rev. 2018;39(3):e13-17.

8 Maciel MG, Enokihara MM, Seize MB, Marcassi AP, Piazza CA, Cestari SD. Elastoma: clinical and histopathological aspects of a rare disease. An Bras Dermatol. 2016;91(5 Suppl 1):39-41.

9 Cotta-Pereira G, Guerra Rodrigo F, Bittencourt-Sampaio S. Oxytalan, elaunin, and elastic fibers in the human skin. J Invest Dermatol. 1976;66(3):143-8.

10 Charoenchon N, Rhodes LE, Pilkington SM, Farrar MD, Watson REB. Differential reorganisation of cutaneous elastic fibres: a comparison of the in vivo effects of broadband ultraviolet B versus solar simulated radiation. Photochem Photobiol Sci. 2018;17(7):88995.
11 Lee DY, Park JH, Shin HT, Yang JM, Jang KT, Kwon GY, et al. The presence and localization of onychodermis (specialized nail mesenchyme) containing onychofibroblasts in the nail unit: a morphological and immunohistochemical study. Histopathology. 2012;61(1): 123-30.

12 Haneke E. CD10 and the nail. J Cutan Pathol. 2017;44(11):907-8.

13 Lee DY, Park JH, Li M, Abudureyimu G, Oh SJ, Shin HT, et al. The concept of nail matrix onychodermis (onychomatricodermis) in the nail unit: histology and elastin immunohistochemistry. J Cutan Pathol. 2019;46(7):490-7.

14 Hanami Y, Yamamoto T. Nodular solar elastoma on the face. J Dermatol. 2019;47(1):e24.

15 Haneke E. Histopathology of the nail: onychopathology. Boca Raton FL: CRC Press; 2017. 